\title{
Fluid uptake in Schirmer papers and its relevance to their employment in tear collection for lysozyme tests
}

\author{
TERENCE J. HYPHER \\ From the Department of Ophthalmology, University of Liverpool
}

\begin{abstract}
SUMMARY An investigation was undertaken into the relationship between the wet length of a standard Schirmer paper and the fluid weight in the $5 \mathrm{~mm}$ tip after a 5-minute moistening period. Immediate weighing after moistening showed that it is unreliable to infer a particular fluid weight in the $5 \mathrm{~mm}$ tip from a known wet length, and it is concluded that such papers will lead to error in lysozyme tests. If the papers are inserted for a period within sealed envelopes, there is found to be a close relationship between wet length and fluid weight in the tip, the papers reaching a stable state at 5 hours. Soaked Schirmer papers were shown to give particularly inconsistent results.
\end{abstract}

Tear samples may be collected for lysozyme estimation by employment of filter paper discs ${ }^{12}$ or Schirmer papers. ${ }^{34}$ In these procedures it is necessary that the weight of each individual sample be determined unless the paper is known to take up a constant quantity of tears. A previous $\operatorname{paper}^{5}$ gave an account of the weight of tears collected by $6 \mathrm{~mm}$ filter paper discs, and the present work was undertaken to investigate fluid uptake in Schirmer papers.

\section{Preliminary investigations}

Preliminary work showed that there was rapid fluid loss by evaporation from moist filter paper samples, and it was necessary to understand and control this factor before further research could be undertaken. Serial weighings of $5 \mathrm{~mm}$ filter paper squares (Whatman no. 41) moistened with water revealed that the evaporation rate varied with relative humidity, but was independent of the weight of fluid in the paper. A series of moist filter paper squares was therefore weighed under differing conditions of relative humidity to compare the evaporation rate with the wet bulb depression of a wet and dry bulb thermometer placed beside the balance. Fifty-three tests were undertaken, each determining mean loss of moisture from two $5 \mathrm{~mm}$ filter paper squares weighed over a period of 10 minutes. Within the temperature range 12.8 to $26.7^{\circ} \mathrm{C}\left(55\right.$ to $\left.80^{\circ} \mathrm{F}\right)$ a very close relationship was

Correspondence to Mr T. J. Hypher, 46 Hendrefoilan Road, Sketty, Swansea SA2 9LT. demonstrated between the rate of evaporation and the wet bulb depression (correlation coefficient $0.97, \mathrm{P}<0.001)$. It was concluded, therefore, that a simple reading of wet bulb depression could replace measurement of evaporation rate. Determination of relative humidity was also unnecessary.

Subsequent experiment showed that the relationship between the length of Schirmer paper wetted and the fluid weight in the first $5 \mathrm{~mm}$ portion is altered by several factors. These factors were covering a section to reduce evaporation, whether one or both surfaces were freely exposed to the air, and the time interval between moistening and weighing even when correction had been made for evaporation loss. It was decided therefore to set up a model resembling the normal Schirmer procedure, in which a paper is placed over the lower lid and moistened by tears for a period of 5 minutes.

\section{Material and methods}

Standardised Schirmer papers $5 \mathrm{~mm}$ wide and $35 \mathrm{~mm}$ long (Whatman no. 41, Halberg and Berens) were taken, and the rounded end was cut off at the $5 \mathrm{~mm}$ notch and discarded, thus leaving a $30 \mathrm{~mm}$ long paper with square-cut end. The first $5 \mathrm{~mm}$ length of this shortened paper was placed on a nonabsorbent surface and lightly covered with a $5 \mathrm{~mm}$ wide strip of plastic adhesive tape, the remaining $25 \mathrm{~mm}$ being so placed that both surfaces were freely exposed. The temperature and wet bulb depression at the site were noted, and by means of a micropipette a $1 \%$ aqueous solution of fluorescein was intermittently applied to the edge of the covered 
end over a period of 5 minutes. The length of moistening, including the covered $5 \mathrm{~mm}$, was then measured, the fluorescein colouration facilitating this reading, after which either of two procedures was followed. In the first the covered $5 \mathrm{~mm}$ end of paper was immediately cut off with a razor blade and the moisture content determined by weighing wet and then reweighing after drying at room temperature. In the second procedure the whole strip was immediately placed in the plastic envelope in which it is supplied, usually 2 strips per envelope, and this was sealed inside with petroleum based gum (Studio Gum) and outside with plastic adhesive tape. (Early trials showed that evaporation from the envelope was not entirely abolished by the tape alone.) After a chosen period of time the strip was removed from the envelope and the $5 \mathrm{~mm}$ tip was cut off and weighed wet and then dried, as in the first procedure. The weight of fluid in the $5 \mathrm{~mm}$ end of Schirmer paper was thus determined for a range of moist lengths and under different conditions of wet bulb depression, both on immediate weighing and after elapse of the following time intervals: $\frac{1}{2}$ hour, $1,2,3,4,5,6$, and 8 hours.

\section{Results}

IMMEDIATE WEIGHING

Trials were conducted under 4 different conditions of wet bulb depression. Eleven papers were tested at $5.8 \mathrm{C}^{\circ}$ depression, and 12 each at 6.9 and $7.5 \mathrm{C}^{\circ}$, but in none of these series was a statistically significant correlation found between wet length of paper and fluid weight in the $5 \mathrm{~mm}$ tip. The tip fluid weight ranged from 1.5 to $3.1 \mathrm{mg}$. At a depression of $5.3 \mathrm{C}^{\circ}$ the correlation between the 2 variables was found to be significant in a trial of 12 papers, and therefore tests were extended to a total of 37 . These confirmed a relationship between wet length and tip fluid weight, but there was still a very wide spread of readings (correlation coefficient $0.62, \mathrm{P}<0.001$ ), and the tip fluid weight ranged from 0.5 to $4.6 \mathrm{mg}$.

\section{DELAYED WEIGHING AFTER SEALING}

IN ENVELOPES

Twenty-one trials were carried out, each consisting on average of 27 papers (range 19 to 49 papers), under conditions of wet bulb depression varying from 2.8 to $7 \cdot 5 \mathrm{C}^{\circ}$ and at time intervals from $\frac{1}{2}$ hour to 8 hours. In every trial a highly significant correlation was found between wet length and fluid weight in the $5 \mathrm{~mm}$ tip (mean correlation coefficient 0.91 , range 0.80 to $0.97, P<0.001$ ). The general pattern of results is best illustrated by the findings at a period of 2 hours in the envelopes (Fig. 1). The Schirmer paper wet length is shown plotted against

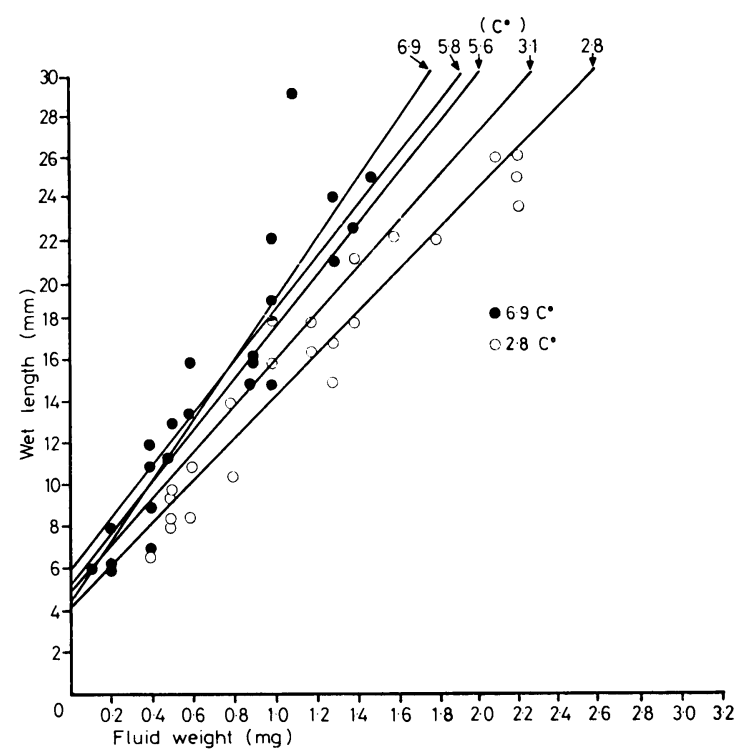

Fig. 1 Two hours. Relationship between wet length and fluid weight in $5 \mathrm{~mm}$ tip of Schirmer paper at differing wet bulb depressions (co-ordinates at 3.1, 5.6, and $5 \cdot 8 C^{\circ}$ depressions omitted for clarity).

fluid weight in the tip, these 2 hour tests being performed at 5 different wet bulb depressions. It is seen that the moist length is directly proportional to the fluid weight, but that papers moistened at a depression of $6.9 \mathrm{C}^{\circ}$ hold less fluid than those at $2 \cdot 8 \mathrm{C}^{\circ}$, this difference increasing with greater wet length. The results at intermediate depressions are seen to lie in order between the highest and lowest depression lines, and it was established that the intervals between these lines related directly to the logarithms of the depressions.

Regression lines were compared statistically by the appropriate $\mathrm{F}$ test. ${ }^{6}$ No significant difference was found between the results at $\frac{1}{2}$ hour and 1 hour, but with further lapse of time there was a narrowing of the gap between high and low depression lines. In addition the graph lines were observed to shift to the left, indicating that fluid was slowly being lost from the tip of the paper.

These changes were seen in the 2 hour and 3 hour graphs, and by 4 hours the gaps between the lines at different depressions had closed completely (no significant difference between 4 hour findings at $6 \cdot 7,6 \cdot 1$, and $3 \cdot 5 \mathrm{C}^{\circ}$ : the correlation coefficient for total 65 papers was 0.94 ).

At 5 hours there had been a further shift of the lines to the left, but no subsequent change was found with 6 or 8 hour papers. Thus, while the difference between high and low depression results 
had been eliminated at 4 hours, the moisture content did not finally become stable in the paper until 5 hours had elapsed.

During the investigations 17 papers, each moistened to about its full length, were found to hold a disproportionately heavy weight of fluid. These were considered to be 'soaked' papers, the fluid content of which was misleading to the trial, and they were therefore discounted (see Discussion).

\section{Discussion}

It has been seen that the rapid drying of Schirmer papers necessitates estimation of fluid content either immediately after the 5 minute moistening period or else after sealing in a container to prevent further evaporation to the atmosphere.

\section{IMMEDIATE WEIGHING}

In 3 of the short trials no significant relationship could be demonstrated between wet length of paper and fluid weight in the $5 \mathrm{~mm}$ tip, while in the fourth, at $5 \cdot 3 C^{\circ}$ depression, a significant relationship was both found and confirmed by extension to a total of 37 papers. Nevertheless, the correlation between the 2 variables was poor, indicating that even in this case it would be unreliable to infer a particular fluid weight from a known moist length. It is possible that more extended trials at other conditions of wet bulb depression would also have produced significant results, but there is no reason to expect the correlation to be any closer.

Bonavida and Sapse ${ }^{3}$ and Pietch and Pearlman ${ }^{4}$ employed the $5 \mathrm{~mm}$ tip of tear-moistened Schirmer strips in lysozyme tests on the assumption that it could be relied upon to hold a constant quantity of fluid. However, in the present work a range of 0.5 to $4.6 \mathrm{mg}$ of fluid has been demonstrated in the limited number of papers tested, and in practice lacrimation producing heavily soaked papers would be likely to give still greater weights. Although the application of unit quantity of fluid to a Schirmer paper may be shown to moisten it to a consistent length, ${ }^{378}$ it is clear that the converse does not follow and that unit length of paper can hold a wide range of fluid weights.

\section{DELAYED WEIGHING}

It was observed that the fluid became stabilised in the paper over a 5-hour period in the envelope. As will be seen later, loss by evaporation within the envelope was slight, and therefore the changes must be accounted for by passage of fluid along the paper. It would seem likely that some form of fluid gradient is present in the Schirmer strip, the moisture lying most thickly at the tip and tapering off to- wards the dry end, and during the period in the sealed envelope the fluid becomes more evenly spread, although still retaining a gradient when finally stabilised. This could explain both the close relationship between tip weight and moist length and the changes which occur with time. A period within the envelope produces much more consistent results than were found on immediate weighing.

\section{SOAKED PAPERS}

It was seen that some papers moistened in the region of their full length at 5 minutes could hold disproportionately high quantities of fluid in the tip. This may be explained on the basis that the paper will accept a large quantity of fluid while being unable to register a wet length greater than $30 \mathrm{~mm}$; also that 5 minutes may occasionally be insufficient for a substantial volume of liquid to reach its expected length of moistening. Hence readings approaching the maximum length must be interpreted with caution. Lysozyme techniques in which soaked Schirmer papers are used ${ }^{9}$ will be subject to particularly uncertain results.

TABLE OF MEAN RESULTS

The findings noted after a period in the sealed envelopes were thought to warrant tabulation of mean results (Table 1). The Table is based on the results at highest and lowest depressions, with logarithmic intervals for intermediate figures. All moist length measurements include the first $5 \mathrm{~mm}$, and any wetting of less than this figure would not be relevant to the present trials.

A previous paper ${ }^{5}$ showed that with filter paper discs moisture could be lost within the container. This factor was therefore examined by serial weighings of 19 envelopes containing moistened Schirmer papers, and the total loss of fluid by evaporation within the envelope and on extraction was found in each case to be $0.2 \mathrm{mg}$ per $5 \mathrm{~mm}$ of moist strip. This weight, which in the case of tears would leave lysozyme in the paper, has therefore been added to all results in the formulation of the Table.

In practice, because evaporation from Schirmer papers containing tears will deposit the lysozyme in the strip, some degree of vapour loss from the envelope is unlikely to affect results, provided sufficient moisture remains to permit the changes found in these trials. It is probable, therefore, that glueing of the envelopes is not essential if they have been well sealed with adhesive tape.

It should be noted that all the trials are based on a relationship of low wet bulb depression at a lower temperature, and high depression at a warmer temperature. It is not known whether the findings would hold good under altered circumstances, as, 
Table 1 Mean weights of fluid in $5 \mathrm{~mm}$ tip after periods in sealed envelope (weights expressed in $\mathrm{mg}$ )

\begin{tabular}{|c|c|c|c|c|c|c|c|c|c|c|c|}
\hline $\begin{array}{l}\begin{array}{l}\text { Period of time in } \\
\text { envelope (hours) }\end{array} \\
\text { Wet bulb } \\
\text { depression ( } C\end{array}$ & \multicolumn{3}{|c|}{$\frac{1}{2}$ and 1} & \multicolumn{3}{|l|}{2} & \multicolumn{3}{|l|}{3} & \multirow{2}{*}{$\begin{array}{l}1 \\
\text { to } 7\end{array}$} & \multirow{2}{*}{$\begin{array}{l}5 \text { and over } \\
3 \text { to } 7\end{array}$} \\
\hline $\begin{array}{l}\text { Wet } \\
\text { length }(\mathrm{mm})\end{array}$ & 3 & $j$ & 7 & 3 & $j$ & 7 & 3 & $j$ & 7 & & \\
\hline 6 & $0 \cdot 3$ & $0 \cdot 3$ & $0 \cdot 3$ & 0.4 & $0 \cdot 3$ & $0 \cdot 3$ & 0.4 & 0.2 & $0 \cdot 1$ & $0 \cdot 2$ & 0.2 \\
\hline 8 & $0 \cdot 6$ & 0.5 & 0.4 & $0 \cdot 6$ & 0.5 & 0.4 & $0 \cdot 6$ & 0.4 & $0 \cdot 3$ & 0.4 & 0.4 \\
\hline 10 & 0.9 & 0.7 & $0 \cdot 6$ & $0 \cdot 8$ & 0.7 & $0 \cdot 6$ & $0 \cdot 8$ & 0.5 & 0.4 & 0.6 & 0.5 \\
\hline 12 & $1 \cdot 2$ & 0.9 & 0.7 & 1.0 & 0.8 & 0.7 & $1 \cdot 0$ & 0.7 & 0.5 & 0.7 & 0.6 \\
\hline 14 & 1.4 & $1 \cdot 1$ & 0.9 & $1 \cdot 2$ & $1 \cdot 0$ & 0.9 & $1 \cdot 2$ & 0.9 & $0 \cdot 7$ & 0.9 & 0.8 \\
\hline 16 & $1 \cdot 7$ & $1 \cdot 3$ & $1 \cdot 0$ & 1.4 & $1 \cdot 1$ & 1.0 & 1.4 & 1.0 & 0.8 & $1 \cdot 1$ & 0.9 \\
\hline 18 & $2 \cdot 0$ & 1.5 & $1 \cdot 2$ & $1 \cdot 6$ & $1 \cdot 3$ & $1 \cdot 1$ & $1 \cdot 5$ & $1 \cdot 2$ & 0.9 & $1 \cdot 3$ & $1 \cdot 1$ \\
\hline 20 & $2 \cdot 2$ & 1.7 & $1 \cdot 3$ & $1 \cdot 8$ & $1 \cdot 5$ & $1 \cdot 3$ & 1.7 & $1 \cdot 3$ & $1 \cdot 1$ & $1 \cdot 5$ & $1 \cdot 2$ \\
\hline 22 & $2 \cdot 5$ & 1.9 & $1 \cdot 5$ & $2 \cdot 0$ & $1 \cdot 6$ & 1.4 & 1.9 & $1 \cdot 5$ & $1 \cdot 2$ & 1.7 & $1 \cdot 3$ \\
\hline 24 & $2 \cdot 8$ & $2 \cdot 1$ & $1 \cdot 6$ & $2 \cdot 1$ & 1.8 & $1 \cdot 6$ & $2 \cdot 1$ & $1 \cdot 6$ & $1 \cdot 3$ & 1.9 & $1 \cdot 5$ \\
\hline 26 & $3 \cdot 1$ & $2 \cdot 3$ & $1 \cdot 8$ & $2 \cdot 3$ & 1.9 & $1 \cdot 7$ & $2 \cdot 3$ & 1.8 & 1.4 & $2 \cdot 1$ & 1.6 \\
\hline 28 & $3 \cdot 3$ & $2 \cdot 5$ & 1.9 & 2.5 & $2 \cdot 1$ & 1.8 & 2.5 & 1.9 & $1 \cdot 6$ & $2 \cdot 3$ & $1 \cdot 7$ \\
\hline 30 & $3 \cdot 6$ & $2 \cdot 7$ & $2 \cdot 1$ & 2.7 & $2 \cdot 3$ & $2 \cdot 0$ & 2.7 & $2 \cdot 1$ & $1 \cdot 7$ & 2.5 & 1.9 \\
\hline
\end{tabular}

$95 \%$ Confidence intervals at mean: $\frac{1}{2}$ and 1 hour, $3.6 \mathrm{C}^{\circ}-0.88 \mathrm{~mm}, 6.96 \mathrm{C}^{\circ}-0.85 \mathrm{~mm} ; 2 \mathrm{hours}, 2 \cdot 8 \mathrm{C}^{\circ}-0.74 \mathrm{~mm}, 6.9 \mathrm{C}^{\circ}-1 \cdot 13 \mathrm{~mm} ; 3 \mathrm{hours}, 2 \cdot 8 \mathrm{C}^{\circ}-$ $0.83 \mathrm{~mm}, 6.7 \mathrm{C}^{\circ}-1.78 \mathrm{~mm} ; 4$ hours. $0.62 \mathrm{~mm} ; 5$ hours and over, $0.63 \mathrm{~mm}$.

for example, a low wet bulb depression at high temperature.

I thank Dr J. R. Green for his invaluable guidance with statistical analyses, and $\mathrm{Mr} \mathrm{R}$. Mapstone and $\mathrm{Mr}$ S. I. Davidson for advice and encouragement.

Schirmer papers were supplied by Knox Laboratories Ltd, Aston Clinton, Bucks; and Studio Gum by Gloy, Manor Park, London E12.

\section{References}

1 Bijsterveld OP van. Diagnostic tests in the sicca syndrome. Arch Ophthalmol 1969; 82: 10-4.

2 Mackie IA, Seal DV. Quantitative tear lysozyme assay in units of activity per microlitre. Br J Ophthalmol 1976; 60: $70-4$.
3 Bonavida B, Sapse AT. Human tear lysozyme. II. Quantitative determination with standard Schirmer strips. Am J Ophthalmol 1968; 66: 70-6.

4 Pietch RL, Pearlman ME. Human tear lysozyme variables. Arch Ophthalmol 1973; 90: 94-6.

5 Hypher TJ. Uptake and loss of tears from filter paper discs employed in lysozyme tests. Br J Ophthalmol 1979; 63: $251-5$.

6 Green JR, Margerison D. Statistical Treatment of Experimental Data. Amsterdam: Elsevier, 1977: 298-305.

7 Scherz W, Doane MG, Dohlman CH. Tear volume in normal eyes and keratoconjunctivitis sicca. Albrecht von Graefes Arch Klin Ophthalmol 1974; 192: 141-50.

8 Lamberts DW, Foster CS, Perry HD. Schirmer test after topical anaesthesia and the tear meniscus height in normal eyes. Arch Ophthalmol 1979; 97 : 1082-5.

9 El Gammal MY, Mostafa MS. Estimation of tears lysozyme in some eye diseases. Bull Ophthalmol Soc Egypt 1971; 64: 285-97. 